in patients, was only found in siblings with increased genotypic risk, raising the possibility of genetic determination. Sibling dysbiosis occurred independently from inflammation. Dysbiosis appears to be an early event in $\mathrm{CD}$ pathogenesis and may be an additional marker of $\mathrm{CD}$ risk.

Competing interests $\mathrm{C}$ Hedin grant/research support from: clinical research fellow funded by core charity, K Taylor: None declared, P Louis: None declared, F Farquharson: None declared, S McCartney: None declared, N Prescott: None declared, A Stagg: None declared, J Lindsay: None declared, K Whelan: None declared.

\section{OC-052 COMPARATIVE EVALUATION OF OUTCOMES IN ADOLESCENTS WITH IBD ON TRANSFER FROM PAEDIATRIC TO ADULT HEALTH CARE SERVICES: A CASE FOR STRUCTURED TRANSITION}

doi:10.1136/gutjnl-2012-302514a.52

${ }^{1} \mathrm{R}$ Cole, ${ }^{2} \mathrm{D}$ Ashok, ${ }^{2} \mathrm{P}$ Kumar, ${ }^{2} \mathrm{~A}$ Razack, ${ }^{2} \mathrm{~A}$ Azaz, ${ }^{2} \mathrm{~S}$ Sebastian. ${ }^{*}$ HullgYork medical school; ${ }^{2}$ Hull \& East Yorkshire NHS Trust, Hull, UK

Introduction Transition and transfer of adolescent IBD patients to adult health care services is considered suboptimal in surveys. There is limited data on patients undergoing transition and transfer. We aimed to evaluate the impact of transition service on clinical and developmental outcomes of adolescent IBD patients on transfer to adult health care services.

Methods We reviewed records of IBD patients diagnosed in paediatric care who has been transferred to the adult IBD service. We extracted data on their transition and transfer arrangements, disease outcomes, surgery requirements, radiation exposure, medication compliance, alcohol and drug use and growth and development. The data was compared between those who attended transition service with those who did not pass through the transition service.

Results 51 patients were identified (29M and 22F). 38 patients had Crohn's disease, 11 ulcerative colitis and two indeterminate. The median age at diagnosis was 14 years (range 9-16 years) and the median age at first visit to adult health care was 18 years. 35 patients went through the transition system (group A) but 16 had no formalised transition arrangement before transfer (group B). Group A patients had a median of three appointments (range 2-7) in transition clinic before transfer. Significantly higher number of group B patients needed surgery within 2 years of transfer when compared to patients in group A ( $26 \%$ vs $17.1 \%, p=0.05)$. Similarly $75 \%$ of patients in group B needed at least one admission when compared to only $28.6 \%$ of group A patients $(p=0.002)$. Non-attendance to clinics was a higher problem in group A patients with $93.75 \%$ having at least one non attendance while $37.1 \%$ of group $B$ failed to attend at least one appointment. In addition, drug compliance rates were higher in the transition group when compared to group $\mathrm{B}(76 \%$ and $37.5 \%$ respectively $\mathrm{p}=0.001$. Higher proportion of transitioned patients achieved their estimated maximum growth potential when completing adolescence. 31 of the 35 patients in group A proceeded to higher education/and or employment while this was achieved only by $50 \%$ of the group $\mathrm{B}$ patients. The mean cumulated IBD related radiation exposure was higher was in group B patients $(17.04 \mathrm{mSv})$ when compared to group A $(7.48 \mathrm{mSv})(p=0.0001)$. There was a trend towards higher dependence on opiates and smoking in group $\mathrm{B}$ patients.

Conclusion In adolescent IBD patients, transition care is associated with better disease specific and developmental outcomes. Prospective studies of different models of transition care in IBD are needed.
Competing interests None declared.

\section{BAPEN symposium: "feeding in chronic conditions" \\ OC-053 AN 800 KCAL NUTRITIONALLY COMPLETE TUBE FEED PROVIDES MORE ADEQUATE NUTRITIONAL INTAKE AND IS PRACTICALLY EASIER AND QUICKER TO USE THAN CURRENTLY USED REGIMENS}

doi:10.1136/gutjnl-2012-302514a.53

${ }^{1} \mathrm{G}$ P Hubbard, ${ }^{*}{ }^{2} \mathrm{H}$ Finch, ${ }^{1} \mathrm{R}$ J Stratton. ${ }^{1}$ Medical Affairs, Nutricia, Trowbridge, UK; ${ }^{2}$ Nutrition and Dietetics, Royal Hospital for Neuro-disability, London, UK

Introduction Some long term, chronically ill, tube fed patients with severe central nervous system impairment, may have lower energy requirements than predicted and need very low energy tube feeding regimens $\left(\sim 800 \mathrm{kcal}\right.$ total energy per day) to maintain weight ${ }^{1 .} 2$ These patients receive a variety of different but nutritionally inadequate regimens, which can be complex and time consuming, with increased risk for errors and contamination ${ }^{3}$ This study aimed to compare the nutritional outcomes and practicality of using current tube feeding regimens, vs a specifically developed ready made $800 \mathrm{kcal}$ nutritionally complete tube feed.

Methods Long term tube fed patients (n 15) with severe neurodisorders (mean age: 51 yrs (SD 14), mean BMI: $24 \mathrm{~kg} / \mathrm{m}^{2}$ (SD 2.5), mean time receiving $\leq 1000 \mathrm{kcal} / \mathrm{d}$ : $3 \mathrm{yrs}$ (SD 3.5)) requiring $\sim 800 \mathrm{kcal} / \mathrm{d}$, received their current tube feeding regimen (either $1000 \mathrm{kcal}$ nutritionally complete tube feeds or a mixture of feeding products (a tube feed, protein powder and powdered vitamin and mineral preparations)) for $1 \mathrm{wk}$, followed by $800 \mathrm{kcal} / 1000 \mathrm{ml}$ per day of a ready made nutritionally complete tube feed (Nutrison 800 Complete Multi Fibre) for 4 wks. Nutritional outcomes (nutritional intakes, body weight) and practicality (ease of use, time to prepare and administer, acceptability and preference) were assessed weekly. NHS research ethics approval for this study was received in January 2011.

Results The proportion of patients meeting their energy requirements $(100 \%$ vs $47 \%$ ), and their RNIs for protein (100\% vs $87 \%$ ) and vitamins \& minerals $(100 \%$ vs $53 \%)$ was substantially greater with the ready made tube feed vs current regimens. Use of the ready made tube feed significantly increased the percentage of patients meeting their weight goals ( $86 \%$ vs $35 \%, p=0.003$ ). $86 \%$ of nursing staff preparing and administering the regimens preferred the ready made tube feed $(p=0.013)$ and rated it better for ease of preparation (100\% vs $78 \%$ ) and use (93\% vs $79 \%)$. Preparation and administration of the current regimens took on average 15-55 min longer per patient per day than the ready made tube feed.

Conclusion The ready made $800 \mathrm{kcal}$ nutritionally complete tube feed provided a more nutritionally adequate intake than current tube feeding regimens. It was also practically easier and quicker to use than current regimens, allowing more appropriate utilisation of healthcare resource and time, providing an easier solution for the use of low energy tube feeding regimens in the home care setting.

Competing interests G Hubbard Employee of: Nutricia, H Finch: None declared, R Stratton Employee of: Nutricia.

\section{REFERENCES}

1. Dickerson RN, Brown RO, Gervasio JG, et al. J Am Coll Nutr 1999;18:61-8.

2. Leone, Pencharz. Clin Nutr 2010;29:370-2.

3. Hubbard, et al. Presented at BAPEN. 2011. 